2015

\title{
Commitment to Breastfeeding in the Context of Phenylketonuria
}

Sandra A. Banta-Wright

George Fox University, sbantawright@georgefox.edu

Sheila M. Kodadek

Oregon Health \& Science University

Gail M. Houck

University of Washington

Robert D. Steiner

University of Wisconsin

Kathleen A. Knafl

University of North Carolina at Chapel Hill

Follow this and additional works at: https://digitalcommons.georgefox.edu/sn_fac

Part of the Medicine and Health Sciences Commons

\section{Recommended Citation}

Banta-Wright, Sandra A.; Kodadek, Sheila M.; Houck, Gail M.; Steiner, Robert D.; and Knafl, Kathleen A., "Commitment to Breastfeeding in the Context of Phenylketonuria" (2015). Faculty Publications - School of Nursing. 12.

https://digitalcommons.georgefox.edu/sn_fac/12 inclusion in Faculty Publications - School of Nursing by an authorized administrator of Digital Commons @ George Fox University. For more information, please contact arolfe@georgefox.edu. 


\title{
Commitment to Breastfeeding in the Context of Phenylketonuria
}

\author{
Sandra A. Banta-Wright, Sheila M. Kodadek, Gail M. Houck, Robert D. Steiner, and Kathleen A. Knafl
}

Correspondence Sandra A. Banta-Wright, $\mathrm{PhD}, \mathrm{RN}, \mathrm{NNP}$, School of Nursing, George Fox University, 414 North Meridian, Newberg, OR 97132.

sbantawright@georgefox.edu

Keywords

breastfeeding

breast milk

infant feeding

newborn

phenylketonuria (PKU)

phenylalanine

\begin{abstract}
Objective: To describe the meaning and importance of breastfeeding to mothers of infants with phenylketonuria (PKU). Design: Qualitative description.

Setting: Mothers from the United States and Canada were recruited from the PKU Listserv and interviewed by telephone.

Participants: Ten breastfeeding mothers with infants who had PKU and were younger than age 36 months.

Methods: Mothers' thoughts, decisions, and experiences of breastfeeding their infants with PKU were collected through telephone interviews. Interviews were transcribed verbatim, and data were analyzed using thematic descriptive analysis in the context of PKU.

Results: Participants felt that that breastfeeding an infant with PKU was the healthiest choice and was therefore worth the labor. These women believed that this was what a loving mother would choose. As they continued to breastfeed their infants after diagnosis, the views of the participants changed. Initially they saw PKU as a disorder and felt that their infants were ill; later they felt that their infants were healthy in spite of PKU. Normal could mean a breastfeeding infant with PKU.
\end{abstract}

Conclusion: Findings demonstrate the importance mothers attribute to breastfeeding and their willingness to invest considerable effort to breastfeed. Health care providers working with these mothers should help them strategize for success.

JOGNN, 44, 726-736; 2015. DOI: 10.1111/1552-6909.12750

$\square$ henylketonuria (PKU) is an autosomal recessive condition related to the metabolism of amino acid. This condition results from mutations in the phenylalanine hydroxylase enzyme (PAH), which is required to metabolize phenylalanine (Phe) to tyrosine (Tyr) in the liver (Blau, van Spronsen, \& Levy, 2010). As a result of the defective $\mathrm{PAH}$ enzyme, Phe and its metabolites accumulate in the blood and eventually the brain and can cause progressive cognitive-neurologic damage in the infant

The prevalence of PKU varies worldwide but is present in every racial and ethnic group. The greatest prevalence of $\mathrm{PKU}$ is in Ireland with one case per 4,500 live births (Zschocke, Mallory, Eiken, \& Nevin, 1997). Turkey follows closely with one case per 5,000 live births (Tuncbilek \& Ozguc, 2007). Finland has the lowest prevalence in Europe with less than one case per 100,000 births (Guldberg, Henriksen, Sipila, Guttler, \& de la Chapelle, 1995). In Latin America, the preva- lence of PKU varies from one case per 25,000 births in Brazil to one case per 52,000 births in Cuba (Borrajo, 2007). In comparison, the prevalence of PKU in Asia varies from one case per 15,000 to one case per 100,500 births in different regions of China (Jiang et al., 2003; Zhan, Qin, \& Zhao, 2009) to one case per 327,000 births in Thailand (Pangkanon, Charoensiriwatana, Janejai, Boonwanich, \& Chaisomchit, 2009).

In the United States, the prevalence of PKU is approximately one case in 20,0000 live births but varies from state to state due to the racial and ethnic makeup of the population (National Institutes of Health Consensus Development Panel, 2001; National Newborn Screening and Genetics Resource Center, 2009). The prevalence in lowa is consistent with the national reported prevalence of approximately one case per 20,000 births (National Newborn Screening and Genetics Resource Center, 2009), whereas in Louisiana, the prevalence is approximately one case per 10,000 live births
The authors report no conflict of interest or relevant financial relationships. 
in the White population and one case per 76,000 live births in the non-White population (Louisana Office of Public Health, 2000). Overall, approximately 400 infants are born each year who are positive for PKU in the United States.

In the United States newborn screening for PKU is performed via tandem mass spectrometry on dried blood spots. If a newborn has an abnormally elevated level of Phe (>190 $\mu \mathrm{mol} / \mathrm{L})$ with an increased Phe-to-Tyr (ratio >3) on the newborn screen, this is a presumptive positive result, and follow-up diagnostic testing and assessment at a pediatric metabolic clinic is needed as soon as possible (Northwest Regional Newborn Screening Program, 2010). Follow-up Phe testing is needed to measure Phe concentrations in the blood with positive diagnostic results revealing increased Phe concentrations (>120 $\mu \mathrm{mol} / \mathrm{L})$ (Donlon, Levy, \& Scriver, 2014).

Because the advent of newborn screening, infants with PKU can be diagnosed before an insidious neurocognitive insult occurs. During the 1960s and the early days of screening, the standard of care for infants diagnosed with PKU was to wean them immediately from breastfeeding and to institute feedings of low-Phe medical formula in conjunction with standard commercial infant formula with the goal to maintain appropriate Phe levels (120-360 $\mu \mathrm{mol} / \mathrm{L}$ ) (Blau et al., 2010; Demirkol et al., 2001; Kanufre et al., 2007). This management plan was believed to be the only effective way to allow for precise titration and measurement of Phe to protect neurological and cognitive development of infants with PKU. As researchers demonstrated that breastfeeding and human breast milk were viable options to the original practice of exclusive formula feeding, more mothers attempted to continue breastfeeding after diagnosis (Cornejo et al., 2003; Ernest, McCabe, Neifert, \& O'Flynn, 1980; Greve, Wheeler, Green-Burgeson, \& Zorn, 1994; Kanufre et al., 2007; McCabe et al., 1989; Motzfeldt, Lilje, \& Nylander, 1999).

Although many mothers successfully continue to breastfeed, many mothers decide not to continue to breastfeed after the diagnosis of PKU (BantaWright, Press, Knafl, Steiner, \& Houck, 2014). In addition, investigators have consistently reported that few mothers of infants with PKU persist in breastfeeding beyond an initial period and breastfeed for a shorter duration than mothers of other healthy term infants (Agostoni, Verduci, Fiori, Riva, \& Giovannini, 2000; Banta-Wright et al., 2014; Banta-Wright, Shelton, Lowe, Knafl, \& Houck,

\section{Breastfeeding infants with phenylketonuria is challenging in part because it is virtually impossible to precisely determine phenylalanine intake.}

2012; Cornejo et al., 2003; Demirkol et al., 2001; Huner \& Demirkol, 1996; Kanufre et al., 2007; Motzfeldt et al., 1999; Segev, Abraham, Anikster, \& Schwartz, 2004; van Rijn et al., 2003).

The National Institutes of Health (2000) consensus statement on PKU encouraged breastfeeding in conjunction with the use of Phe-free medical formula. In an international survey, MacDonald and colleagues (2006) examined the feeding recommendations of health care providers in various metabolic centers in Europe, South America, United States, Australia, and New Zealand. They found no universal approach to feeding infants with PKU. Treatment management varied among countries and between metabolic centers within countries. However, there was consensus regarding the recommendation of Phe-free medical formula in combination with breastfeeding. In 2011, the National PKU Alliance published "My PKU Binder," a comprehensive resource for parents and individuals with PKU that briefly mentions that breast milk contains less Phe than standard commercial infant formula. This binder, a trusted resource for mothers learning about PKU, provides much needed general information about PKU but lacks specific guidelines for successfully breastfeeding infants with PKU (e.g., guidance on maintaining a breast milk supply when having to alter breast milk intake to maintain Phe levels within the desired range).

Although PKU is a classic Mendelian disease, it has variable clinical presentation and severity due to the different mutations in the gene-encoding $\mathrm{PAH}$ enzyme. The combinations of the different mutations result in varying degrees of residual PAH activity level (Guldberg et al., 1994). The residual PAH enzyme activity reflects Phe tolerance. Phenylketonuria is classified based upon the severity of the elevated Phe levels. The normal range of blood Phe concentrations is 50 to $110 \mu \mathrm{mol} / \mathrm{L}$ (Donlon et al., 2014). There are four different phenotypes: classical PKU, moderate PKU, mild PKU, and mild hyperphenylalaninemia (Blau, Hennermann, Langenbeck, \& LichterKonecki, 2011). Yet classification during the newborn period is difficult to determine as Phe concentrations have not had time to reach their peak values, and treatment is initiated before
Robert D. Steiner, MD, is the Executive Director, Marshfield Clinic Research Foundation, Chief Science Officer, Marshfield Clinic, Marshfield, WI, and a visiting professor, University of Wisconsin, Madison, WI.

Kathleen A. Knafl, PhD, FAAN, is a professor in the School of Nursing,

University of North Carolina-Chapel Hill, Chapel Hill, NC. 
allowing the levels to peak. Usually by age 2 years, the determination of the degree of Phe tolerance is predictable (van Spronsen et al., 2009).

Breastfeeding an infant with PKU is challenging and includes feeding at breast and bottle feeding expressed breast milk. Mothers typically offer breast milk by one of three methods based upon recommendations from their metabolic clinic. (a) Mothers may provide a fixed amount of Phefree medical formula followed by breastfeeding until satiety (Greve et al., 1994; Motzfeldt et al., 1999), (b) provide a fixed amount of expressed breast milk or a fixed time limitation of breastfeeding followed by Phe-free medical formula until satiety (Acosta \& Yannicelli, 2001), and (c) or alternate between breastfeeding and Phe-free medical formula feedings (van Rijn et al., 2003). All methods are dependent on the infant's serial weekly to twice weekly blood Phe levels. Generally, mothers obtain Phe specimens on their infants by performing heel sticks and forward the dried filter paper specimen to the laboratory for analysis. After the laboratory receives the specimen, Phe results are available in 24 to 48 hours. If the Phe level is elevated or diminished based on the clinic's protocol, the clinic contacts the mother and the dietary feeding plan is adjusted. If Phe levels are elevated, breastfeeding is decreased; if levels are diminished, breastfeeding is increased. Followup appointments for newborns with newly diagnosed PKU range from weekly for several weeks, to every other week, to monthly by the first 12 months. These appointments are in addition to pediatric visits for regular newborn-infant care. During this time, mothers must breast pump frequently enough to maintain their breast milk supply.

Although the investigators of breastfeeding infants with PKU have focused on management strategies to facilitate the adaption of breastfeeding while maintaining desired Phe levels, notably absent are any studies to address the practice of breastfeeding infants with PKU from mothers' perspectives. Therefore, the purpose of this study was to describe the meaning and importance of breastfeeding to mothers of children with PKU. Our goal was to consider the underlying mind-set and beliefs that influence the decision to continue to breastfeed after the diagnosis of PKU despite challenges.

\section{Methods}

Design and Participants

This was a two-phase mixed methods study. The first phase was an Internet survey completed by mothers who had children with PKU and resided in the United States and Canada. The goal of the quantitative phase was to explore the rate of breastfeeding before and after diagnosis of PKU in a sample. In the sample, 119 mothers completed a survey on their experiences feeding infants with PKU. Of these mothers, 103 mothers had one child with PKU whereas 16 mothers had two or more children with PKU. Mothers with one child with PKU ranged from age 21 to 63 years with a mean of $35.6 \pm 6.98$ years and the majority were in their thirties ( $n=64$, mode $=34)$. Nearly all the mothers were married or partnered. In addition, the survey sample reflected a well-educated group; all mothers were at least high school graduates, and more than two thirds $(n=72)$ were college graduates. Their infants were healthy term newborns with elevated Phe levels that ranged from 240 to 2,520 $\mu \mathrm{mol} / \mathrm{L}$ with a mean of $948 \pm 601 \mu \mathrm{mol} / \mathrm{L}$ on the confirmatory testing after an abnormal newborn screen. Initially 89 mothers breastfed, but after the diagnosis, only 72 mothers continued to breastfeed. This decrease was significant (McNemar's $\chi^{2}=30.333, p<.001 ; n=72$ vs. $n=89$ ) (BantaWright et al., 2014).

The second phase of the study entailed qualitative interviews with a subsample of mothers from the survey. The goal of the interviews was to further explore mothers' breastfeeding experiences. For the interviews, the inclusion criteria were at least age 21 years or older and initiated breastfeeding an infant with PKU. There were no restrictions on the length of time the mother had breastfed, but only mothers of one child with PKU were recruited. In addition, the breastfed infant with PKU needed to be younger than age 36 months at the time of the interview. Of the 103 mothers who completed the survey and expressed a willingness to be interviewed, 23 mothers met the sample criteria for the qualitative phase of the study. Overall, the 23 mothers were predominately White, well educated, in their thirties, had breastfed for at least 4 months, and lived in various geographic regions in the United States and Canada. Ten mothers were selected to reflect a broad range of demographic variables: urban or rural residence, ethnicity, gravida status, education, marital status, employment, and family income. Their infants were healthy term infants with initial Phe levels ranging from 360 to $720 \mu \mathrm{mol} / \mathrm{L}$. For this analysis, a descriptive qualitative approach was used to describe the meaning and importance of breastfeeding for mothers of children with PKU. This study was approved by the Oregon Health \& Sciences University Institutional Review Board. 


\section{Table 1: Sample Questions From Interview Guide}

\begin{tabular}{|c|c|}
\hline Family Management Topic & Question \\
\hline \multicolumn{2}{|l|}{ Defining the Situation } \\
\hline Self & Tell me about your initial reaction to the PKU diagnosis. \\
\hline Family & Tell me how you explained PKU to the members of your family and friends. \\
\hline Child & Tell me how breastfeeding changed once the diagnosis of PKU was made. \\
\hline \multicolumn{2}{|l|}{ Management Behaviors } \\
\hline Self & Tell me about your decision to continue breastfeeding your infant after the diagnosis of PKU. \\
\hline Family & Tell me about the support or lack of support that you received in managing your infant's PKU. \\
\hline Child & Tell me about what it was like to breastfeed your infant with PKU. \\
\hline \multicolumn{2}{|l|}{ Perceived Consequences } \\
\hline Self & Tell me about your perception of changes in how you parent or take care of the child with PKU. \\
\hline Family & Tell me about the experience of PKU for your family. \\
\hline Child & Tell me how you think PKU will affect your child as he/she grows. \\
\hline
\end{tabular}

\section{Data Collection}

Mothers who completed the Internet survey and met the inclusion criteria were informed about the study by the principal investigator. After obtaining informed consent from each mother, in-depth telephone interviews were conducted and digitally recorded. The digitally recorded telephone interviews ranged from 56 to 125 minutes with a mean of 92 minutes. A detailed three-page interview guide was developed to reflect the study purpose and objectives. A sample of the questions is provided in Table 1. In addition, mothers were encouraged to expand on any topics they introduced that were not included in the guide. As a starting point, mothers were asked, "Tell me about a typical day of breastfeeding your infant." This question was designed to elicit a full picture of the day-to-day experience of breastfeeding an infant with PKU. Probing questions were used to gain a detailed description of the meaning participants ascribed to breastfeeding infants with PKU. Field notes about the context (e.g., interruptions, background noises) and tone of the interview were recorded immediately after each interview. At the completion of the interview, mothers were sent $\$ 20$ gift certificates. Data collection occurred between February 2011 and June 2012.

\section{Analysis}

After the interviews were transcribed verbatim and checked for accuracy, a descriptive thematic approach was used to complete the analysis (Miles
\& Huberman, 1994; Saldana, 2009). The intent was to analyze the meaning and importance of breastfeeding infants with PKU from the perspectives of their mothers. Rules and definitions were created to ensure that coding occurred consistently throughout the narratives (Miles \& Huberman, 1994; Saldana, 2009). For this analysis, coded data from all interviews that were related to the meaning and importance of breastfeeding an infant with PKU were reviewed. Mothers' descriptions of the meaning and importance of breastfeeding an infant with PKU were grouped together to form categories. Thematically similar categories and data were combined to form themes. Emerging themes were compared among transcripts during data analysis to establish their linkages across categories (Ayres, Kavanaugh, \& Knafl, 2003).

Several techniques were implemented to enhance the study quality. To ensure consistent style of interviewing, the principal investigator completed all the interviews. To address researcher bias that might influence analysis, initial transcripts were reviewed by coauthors who found no evidence of leading questions or inappropriate probing. Coauthors also provided input throughout the analysis on the development of coding categories, the coding process, and the interpretation of study results. Differences in coding were resolved with conferencing among team members to reach consensus about coding, and to confirm agreement on the overarching theme and subthemes (Patton, 2002). 
To enhance the trustworthiness of the data, a detailed audit trail was maintained that documented all methodological and analytical decisions.

\section{Results}

\section{Labor of Love}

The central theme Labor of Love reflected the commitment of mothers to breastfeed despite a diagnosis of PKU. Prior to diagnosis, mothers exclusively breastfed their infants. In so doing, they expressed their support of the benefits of breastfeeding and breast milk. Mothers reported that following the diagnosis of PKU they decided to continue breastfeeding, even though this required increased effort. For these mothers, breastfeeding required that they prepare and bottle feed Phefree medical formula as instructed by a health care provider (usually a dietitian) to maintain their infants' Phe levels within the desired range. Sometimes expressed breast milk or standard commercial infant formula was required in addition to the medical formula. These mothers needed to breast pump to maintain their breast milk supplies. Pumping included the time to pump, clean pumping equipment after each use, and store expressed breast milk in appropriate containers for freezing or refrigeration. Mothers linked their willingness to undertake the extra work of breastfeeding to their commitment to doing what was best for the infants.

During this time, mothers also were orchestrating the care of their infants. As one mother commented, "It would be easier if I could just breastfeed him. But, I can't. It would be easier if he was exclusively formula fed, but he's not." Mothers wanted to provide the best nutrition to their infants and believed the extra work required to continue breastfeeding was worth the effort. For these mothers, breastfeeding in the context of PKU was truly a labor of love, and this commitment broadens the definition of successful breastfeeding in this unique group of mothers. See Figure 1 for a summary of the main and subthemes.

Committing to Breastfeed After the Diagnosis. The first subtheme we identified was Committing to Breastfeed After the Diagnosis. Although all mothers planned on breastfeeding, after diagnosis they explored the option to continue to breastfeed. UItimately, they recommitted to breastfeeding despite the diagnosis. Recommitting entailed quickly learning about PKU and the special nutritional needs of their infants. Mothers described a steep learning curve as they came to understand the disorder more fully and implications for their infants and family. One mother described continuing to breastfeed as a relief that was made possible by support from the clinic's staff:

Because the clinic supported it, our doctor was very into the "breastfeeding was best." It really wasn't a choice. It wasn't a decision. It was already our plan. Thus, we didn't have to deviate from our plan. It was a relief that we were able to keep doing it.

Other mothers described their decisions to recommit to breastfeeding as based on the realization that breast milk was lower in Phe than standard

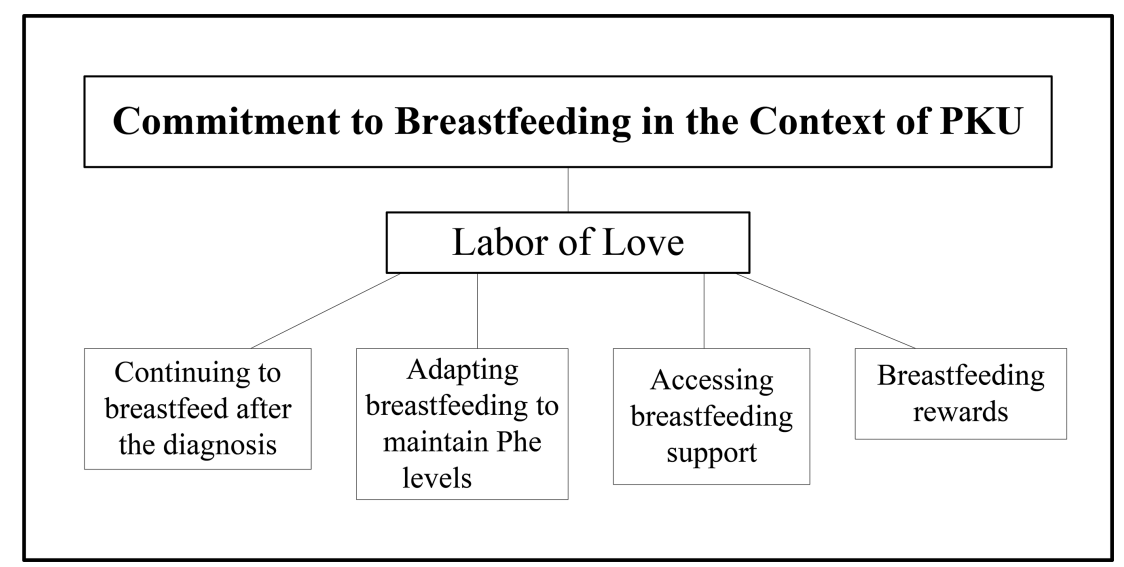

Figure 1. Themes and subthemes related to participants' commitment to breastfeed in the context of PKU.

Note. Phe $=$ phenylalanine, $\mathrm{PKU}=$ phenylketonuria. 
commercial infant formula, the closeness between mother and infant, and the regular nutritional benefits of breast milk for infants:

Our dietitian said at the very beginning about how breast milk was ... lower in phenylalanine than [the standard commercial infant] formula. In my mind, that meant that it would be better for me to keep trying to give him breast milk as much as I could.

\section{Another mother stated:}

It really did not make sense to me that since he still needed natural protein in this diet [why not give him] ... the most natural protein ... breast milk. It just added to the argument of why I should continue.

Breastfeeding symbolized the continuation of the unique biological connection between the mother and infant. Mothers described the experience as a special "closeness" or "bonding" that they felt with their infants because of breastfeeding, "Knowing that it was a way that I could bond with her.... It was easy to continue to breastfeed her because knew that it was the best thing for her."

Although mothers articulated the general benefits of breast milk, a few mothers decided to continue to breastfeed to mitigate the effects of PKU, because breast milk could improve their infants' cognitive and neurological outcomes:

I knew that breast milk would provide benefits that could not be matched with [standard commercial infant] formula. I also knew that breastfed babies tended to have higher IQs. I thought that if she is going to be in a position where her IQ would already be lower that it would make more sense to me to do everything that I could to protect her brain. Maybe the breast milk would counter balance it a little bit.

Consequently, their infants continued to breastfeed and received the benefits of breast milk and breastfeeding.

Adapting Breastfeeding to Maintain Phe Levels. The second subtheme related to adapting breastfeeding, which meant mothers had the patience and perseverance to make breastfeeding work while maintaining Phe levels. One mother shared modifying her breastfeeding plans as, "You do what you need to do." Immediately after diagnosis, mothers used a variety of approaches to combine
Mothers wanted to provide the best nutrition for their infants with phenylketonuria, which meant limiting breastfeeding while bottle feeding phenylalanine-free medical formula.

breastfeeding and bottle feeding Phe-free medical formula that ranged from offering a small amount of medical formula at each feeding to alternating breastfeeding and bottle feeding medical formula. In addition, mothers developed creative strategies to encourage their infants to bottle feed Phe-free medical formula, such as regulating the temperature of the formula, combining expressed breast milk with the formula, and using specific bottles and nipples.

These mothers worked through numerous challenges presented by fluctuating Phe levels and ever-changing treatment plans:

I breastfed for 7 months. During that time, [how much I could breastfed] ... fluctuated because we monitored [Phe] levels every week. I would have to increase breastfeeding if levels were too low and decrease breastfeeding if they went too high.

The majority of the mothers realized shortly after the PKU diagnosis that they needed to be proactive to maintain their breast milk supplies, and they started breast pumping after feeding their infants the medical formula. Nonetheless, mothers also reported it was a challenge to keep up a milk supply even with a "powerful" breast pump:

Having a good pump, a really good pump, really did it because the issues that arise with breastfeeding and simultaneously bottle feeding are always related to supply. Because your infant has not nursed as frequently as an exclusively breastfed baby, your supply can wane.

For some mothers even routine pumping after bottle feeding medical formula was not enough to keep up their milk supplies. A few mothers were prescribed domperidone, and others were encouraged to use herbal supplements to boost their breast milk supply in combination with breast pumping and breastfeeding. They also reported that "finding the time to breast pump ... wasn't easy" while continuing with their other household duties, child care responsibilities, and for some, returning to their careers. Yet mothers persisted and described how they integrated breast pumping into their busy schedules. 
Accessing Breastfeeding Support. The third subtheme to emerge was related to supportive resources used by mothers to help them maintain their commitment to breastfeeding. Mothers sought out resources and support from other mothers who had breastfed or were currently breastfeeding infants with PKU and who understood what they were going through. Some were able to locate another mother close by, and these one-on-one exchanges provided participants with the support they needed to continue breastfeeding: "When my son was about 2 months old, I talked with another mom who had breastfed her son with PKU ... for almost 11 months that encouraged me and definitely kept me going toward the end."

However, most mothers were unable to find another mother who lived within their geographical area and instead sought support via the Internet:

I joined the PKU Listserv ... I started sending out emails: Need breastfeeding advice, Having supply issues with PKU baby - How do you increase, how did you increase your supply from mothers who have done it? How did you manage? ... I had 20 responses within 24 hours... They (wrote) this is what I did, this is how we managed, and this is what my clinic expected. My experience with the Listserv in getting all those responses was a positive thing.

Other mothers who joined the PKU Listserv also found it a valuable resource. Although they did not all post questions, they learned from various conversations covering topics of interest.

Even though there are many members of the metabolic team, dietitians were identified by all mothers as the primary support. One mother shared, "Our dietitian was extremely helpful and said, 'Your breast milk is good for her. This is the right thing to do.' She was very supportive that way." The majority of mothers also identified their husbands as supportive of breastfeeding, "I had a husband who believed in it [breastfeeding]. He really believed that breastfeeding was the best thing." In addition, mothers received support from family and friends who lived nearby:

Most of the breastfeeding information, I got from my mom from resources that she had. I think that her breastfeeding knowledge base really helped. She called almost every lactation consultant that she knew and they all kind of teamed up ... I think that if she had not been as supportive that it [breastfeeding] would have been harder.

All mothers were able to find information about PKU or information about breastfeeding but not breastfeeding infants with PKU, "I tried to go on the web to do some searches. I found a lot of information on breastfeeding in general, but not on breastfeeding and PKU." Mothers identified a clear lack of written information about breastfeeding infants with PKU and any written support was dependent on their ability to integrate information from these two disparate bodies of knowledge.

Breastfeeding Rewards. The fourth subtheme reflected the belief that in spite of the breastfeeding challenges, the rewards outweighed the work associated with breastfeeding infants with PKU:

I am so grateful that we were able to still breastfeed her. Even with the cracked and bleeding nipples, the thrush.... It wasn't always very fun and it made me cry. I'm really grateful that we were able to breastfeed as I believe that it [breastfeeding] is the best thing.

In committing to continue breastfeeding after the diagnosis, these mothers carried out a unique maternal activity that contributed to their views of themselves as good mothers:

It's been really great because I never wanted to look back ... at his first year and say I wish that I could have done something differently. I think when you find out that you have a child with PKU that you kind of overanalyze their development. I think for a long time that I would get really hung up on "well, he is not looking at me" and "he crawled a lot later than his sibling. He is definitely behind in gross motor, but he is not at all developmentally delayed." His doctors are like "he is totally on track." For a long time I really didn't believe that, but now [I see him] doing really so well. His verbal skills are great. His fine motor skills are awesome. He is so communicative. He is so smart. I feel so proud of myself. I have no idea if breastfeeding had any correlation to that, but I think that if I hadn't done that, I might have thought that well maybe I would have done something differently. So I think that it [breastfeeding] really was a labor of love. 
Over time, these mothers began to view their infants as normal, healthy children who happened to have PKU. This was in part a validation of their breastfeeding decisions. Breastfeeding gave them a way to view their infants as normal and to achieve a sense of normalcy in everyday life. One mother summed it up: "He has PKU, but he isn't PKU. It is just one aspect of his life. It is not his whole life."

\section{Discussion}

In this study, we explored the meaning and importance of breastfeeding to mothers with infants diagnosed with PKU. The reports of their experiences revealed the depth and breadth of their commitment to continue breastfeeding after the diagnosis. Although many of the experiences of the mothers were similar to those of mothers of term infants, this study provided valuable insights into the commitment that is necessary to breastfeed an infant with PKU. Several researchers reported that being committed to breastfeeding influenced mothers to persist with breastfeeding their term infants (Blyth et al., 2002; Bottorff, 1990; Humenick, Hill, \& Wilhelm, 1997; Nelson \& Sethi, 2005). In this study, the theme of commitment provided a way to understand and characterize the participants' unique experiences. Their commitment to breastfeeding was evident in their decisions to continue breastfeeding after diagnosis. This decision required that they adapt breastfeeding to manage PKU and to overcome challenges they faced with common breastfeeding problems and fluctuating Phe levels. Thus, the commitment to breastfeeding was a labor of love.

Fluctuating Phe levels provided many challenges, including ever-changing treatment plans and increased workload of breastfeeding, bottle feeding, and breast pumping. Despite weekly to twice weekly adaptations in breastfeeding plans, mothers continued to supply their infants with the best natural source of nutrition. At any time they could have stopped or given up, but instead they made a commitment to breastfeed their infants that tied them to their infants in a special way. This aspect of laboring out of love and commitment to continue breastfeeding broadens the definition of successful breastfeeding in this unique group of mothers.

For mothers of healthy term infants, there are usually many options for help with breastfeeding issues, such as breastfeeding clinics and postpartum nurses, as well as friends and family. Many resources are available at the library, in book stores, and in lay journals. Even mothers of infants who
Mothers wanted more support and encouragement from their families, friends, and health care providers as they continued to breastfeed after the diagnosis of phenylketonuria.

are preterm or critically ill and in the NICU have available resources in the nurses who care for their infants who are premature or critically ill, in-house lactation consultants, and other mothers who have or are breastfeeding/breast pumping for their infants. Since Meier's research on breastfeeding the premature infant (Meier, 2001, 2003b; Meier et al., 2000; Meier et al., 2008; Meier, Engstrom, Janes, Jegier, \& Loera, 2012; Meier, Furman, \& Degenhardt, 2007), there has been a growing knowledge base about breastfeeding the infants who are the smallest and most critically ill. Related publications have been published in lay journals and pamphlets typically available in the NICU. No such resources are available for mothers who wish to breastfeed infants with PKU.

In this study, mothers struggled to locate written information about breastfeeding infants with PKU. We searched for resources for mothers who are breastfeeding infants with PKU. We found Tips for Breastfeeding a Baby With PKU (PKU News, 2006). Unfortunately, this web page has not been updated in 9 years. Even the most recent edition of Breastfeeding: A Guide for the Medical Profession (Lawrence \& Lawrence, 2010) falls short: the section on breastfeeding infants with PKU cites the Ernest et al. (1980) study, which is no longer available from the publisher. Consequently, there is a lack of current, evidence-based information for these mothers who want and need resources related to breastfeeding infants with PKU similar to those developed for breastfeeding premature infants (Meier, 2003aa). To fill this gap, a resource for breastfeeding infants with PKU is being developed in association with the National PKU Alliance.

This study provides the first thematic description from mothers' perspectives of the meaning and importance of breastfeeding infants with PKU and also extends knowledge of the needs of these mothers. Research in this area will provide a scientific base from which to design and test evidencebased strategies to help these mothers. In addition, education can provide clinicians with tools to support mothers to successfully breastfeed their infants with PKU. Finally, research about human milk and lactation that includes infants with inborn errors of metabolism, such as PKU, will be important to inform clinicians and parents alike. 
Implications for Practice

Our findings suggest that nurses working with mothers should be alert to their need for support and encouragement to breastfeed after diagnosis of PKU. The emphasis that mothers in the study placed on support and encouragement suggests that they want more support from their families, friends, and health care providers. As mothers integrate two different bodies of knowledge related to breastfeeding and PKU, they need to have their concerning questions answered in a timely fashion. In addition, mothers want words of encouragement as breastfeeding an infant with PKU is challenging and disheartening at times. Providing support also means providing anticipatory guidance. To be able to continue breastfeeding while supplementing with Phe-free medical formula, mothers need a powerful breast pump to help them maintain breast milk supplies. Mothers should be encouraged to obtain hospital-quality electric breast pumps with double collection kits so that both breasts are emptied simultaneously and for long-term breast pumping. The nurse can provide a list of convenient places to obtain a hospital-quality electric breast pump and should discourage the use of smaller electric or battery-operated breast pumps that seldom provide adequate breast stimulation to maintain an adequate milk supply. In addition, nurses can work with mothers to develop a breast pumping schedule while incorporating PKU management, integrating other family responsibilities, and for some, returning to their careers.

\section{Limitations}

This study included a small sample of mothers who were predominately White, married, and well educated. The relatively high educational and income levels of this sample are consistent with data that these women would be most likely to initiate and continue breastfeeding. Additionally, the clinics where mothers and infants received care may have emphasized the significance of infant health benefits when they counseled the mothers about continuing to breastfeed after diagnosis. The knowledge of breastfeeding benefits may have been a strong motivator for mothers to persevere with their breastfeeding efforts. The sample limits the transferability of the findings, but the results provide further insight into breastfeeding infants with PKU.

\section{Conclusion}

We present findings from a qualitative study in which mothers who breastfed their infants with
PKU were interviewed regarding the meaning and importance of breastfeeding in this situation. Analysis of the interviews with mothers revealed one central theme, Labor of Love: Commitment to Breastfeeding in the Context of PKU. The experiences of the participants demonstrated their commitment to breastfeeding despite the diagnosis of PKU, the importance mothers attribute to breastfeeding, and their willingness to invest considerable effort to breastfeed.

\section{Acknowledgment}

Funded by grant number F31NR01963, Mothers Experience Breastfeeding Infants with PKU and by grant number T32NR007106, Biobehavioral Nursing Training Program.

\section{REFERENCES}

Acosta, P. B., \& Yannicelli, S. (2001). Protocol 1: Phenylketonuria. The Ross metabolic formula system: Nutrition support protocols (4th ed., pp. 1-32). Columbus, OH: Ross Products Division.

Agostoni, C., Verduci, E., Fiori, L., Riva, E., \& Giovannini, M. (2000). Breastfeeding rates among hyperphenylalaninemic infants. Acta Paediatrica, 89(3), 366-367.

Ayres, L., Kavanaugh, K., \& Knafl, K. A. (2003). Within-case and acrosscase approaches to qualitative data analysis. Qualitative Health Research, 13(6), 871-883.

Banta-Wright, S. A., Press, N., Knafl, K. A., Steiner, R. D., \& Houck, G. M. (2014). Breastfeeding infants with phenylketonuria in the United States and Canada. Breastfeeding Medicine, 9(3), 142-148.

Banta-Wright, S. A., Shelton, K. C., Lowe, N. D., Knafl, K. A., \& Houck, G. M. (2012). Breast-feeding success among infants with phenylketonuria. Journal of Pediatric Nursing, 27(4), 319-327. doi:10.1016/j.pedn.2011.03.015

Blau, N., Hennermann, J. B., Langenbeck, U., \& LichterKonecki, U. (2011). Diagnosis, classification, and genetics of phenylketonuria and tetrahydrobiopterin $(\mathrm{BH} 4)$ deficiencies. Molecular Genetics and Metabolism, 104(Suppl), S2-S9. doi:10.1016/j.ymgme.2011.08.017

Blau, N., van Spronsen, F. J., \& Levy, H. L. (2010). Phenylketonuria. Lancet, 376(9750), 1417-1427. doi:10.1016/S01406736(10)60961-0

Blyth, R., Creedy, D. K., Dennis, C. L., Moyle, W., Pratt, J., \& De Vries, S. M. (2002). Effect of maternal confidence on breastfeeding duration: An application of breastfeeding self-efficacy theory. Birth, 29(4), 278-284.

Borrajo, G. J. (2007). Newborn screening in Latin America at the beginning of the 21st century. Journal of Inherited Metabolic Disease, 30(4), 466-481. doi:10.1007/s10545-007-0669-9

Bottorff, J. L. (1990). Persistence in breastfeeding: A phenomenological investigation. Journal of Advanced Nursing, 15(2), 201-209.

Cornejo, V., Manriquez, V., Colombo, M., Mabe, P., Jimenez, M., De la Parra, A., ... Raimann, E. (2003). Phenylketonuria diagnosed during the neonatal period and breast feeding. Revist Medica de Chile, 131(11), 1280-1287.

Demirkol, M., Huner, G., Kuru, N., Donmez, S., Baykal, T., \& Seckin, Y. (2001). Feasibility of breastfeeding in inborn errors of metabolism: Experience in phenylketonuria. Annal of Nutrition and Metabolism, 45(Suppl 1), 497-498. 
Donlon, J., Levy, H., \& Scriver, C. R. (2014). Hyperphenylalaninemia: Phenylalanine hydroxylas deficiency. In D. Valle, A. L. Beaudet, B. Vogelstein, K. W. Kinzler, S. E. Antonarakis, K. Gibson, \& G. Mitchell (Eds.), The online metabolic and molecular bases of inherited disease (OMMBID). New York, NY: McGraw-Hill. doi:10.1036/ommbid.97

Ernest, A. E., McCabe, E. R. B., Neifert, N. R., \& O'Flynn, M. E. (1980). Guide to breast feeding the infant with PKU (DHHS Publication \#79-5110). Washington, DC: U.S. Government Printing Office.

Greve, L. C., Wheeler, M. D., Green-Burgeson, D. K., \& Zorn, E. M. (1994). Breast-feeding in the management of the newborn with phenylketonuria: A practical approach to dietary therapy. Journal of the American Dietetic Association, 94(3), 305309.

Guldberg, P., Henriksen, K. F., Sipila, I., Guttler, F., \& de la Chapelle, A. (1995). Phenylketonuria in a low incidence population: Molecular characterisation of mutations in Finland. Journal of Medical Genetics, 32(12), 976-978.

Guldberg, P., Levy, H. L., Koch, R., Berlin, C. M., Jr., Francois, B. Henriksen, K. F., \& Guttler, F. (1994). Mutation analysis in families with discordant phenotypes of phenylalanine hydroxylase deficiency. Inheritance and expression of the hyperphenylalaninaemias. Journal of Inherited Metabolic Disease, 17(6), 645651

Humenick, S. S., Hill, P. D., \& Wilhelm, S. (1997). Postnatal factors encouraging sustained breastfeeding among primiparas and multiparas. Journal of Perinatal Education, 6(3), 33-45.

Huner, G., \& Demirkol, M. (1996). Breast-feeding and phenylketonuria. Istanbul, Turkey: Turkish Society for PKU.

Jiang, J., Ma, X., Huang, X., Pei, X., Liu, H., Tan, Z., \& Zhu, L. (2003) A survey for the incidence of phenylketonuria in Guangdong, China. Southeast Asian Journal of Tropical Medicine and Public Health, 34(Suppl 3), 185

Kanufre, V. C., Starling, A. L., Leao, E., Aguiar, M. J., Santos, J. S. Soares, R. D., \& Silveira, A. M. (2007). Breastfeeding in the treatment of children with phenylketonuria. Journal de Pediatria 83(5), 447-452. doi:10.2223/JPED.1672

Lawrence, R. A., \& Lawrence, R. M. (2010). Breastfeeding infants with problems. In Breastfeeding: A guide for the medical professional (7th ed., pp. 474-514). Maryland Heights, MO: Elsevier Mosby.

Louisiana Office of Public Health. (2000). PKU in Louisana. New Orleans, LA: Department of Health and Hospitals. Retrieved from http://www.dhh.louisiana.gov/assets/oph/Center-PHCH/CenterCH/infectious-epi/LMR/2000-2010/2000/LMR2000_03.pdf

MacDonald, A., Depondt, E., Evans, S., Daly, A., Hendriksz, C. Chakrapani, A. A., \& Saudubray, J. M. (2006). Breast feeding in IMD. Journal of Inherited Metabolic Disease, 29(2-3), 299303.

McCabe, L., Ernest, A. E., Neifert, M. R., Yannicelli, S., Nord, A. M., Garry, P. J., \& McCabe, E. R. (1989). The management of breast feeding among infants with phenylketonuria. Journal of Inherited Metabolic Disease, 12(4), 467-474.

Meier, P. P. (2001). Breastfeeding in the special care nursery. Prematures and infants with medical problems. Pediatric Clinics of North America, 48(2), 425-442.

Meier, P. P. (2003a). Breastfeeding your premature baby. Columbus, $\mathrm{OH}$ : Abbott Laboratories, Inc.

Meier, P. P. (2003b). Supporting lactation in mothers with very low birth weight infants. Pediatric Annals, 32(5), 317-325.

Meier, P. P., Brown, L. P., Hurst, N. M., Spatz, D. L., Engstrom, J. L., Borucki, L. C., \& Krouse, A. M. (2000). Nipple shields for preterm infants: Effect on milk transfer and duration of breast- feeding. Journal of Human Lactation, 16(2), 106-114; quiz 129131.

Meier, P. P., Engstrom, J. L., Hurst, N. M., Ackerman, B., Allen, M., Motykowski, J. E., ... Jegier, B. J. (2008). A comparison of the efficiency, efficacy, comfort, and convenience of two hospital-grade electric breast pumps for mothers of very low birthweight infants. Breastfeeding Medicine, 3(3), 141-150. doi:10.1089/bfm.2007.0021

Meier, P. P., Engstrom, J. L., Janes, J. E., Jegier, B. J., \& Loera, F. (2012) Breast pump suction patterns that mimic the human infant during breastfeeding: Greater milk output in less time spent pumping for breast pump-dependent mothers with premature infants. Journal of Perinatology, 32(2), 103-110. doi:10.1038/jp.2011.64

Meier, P. P., Furman, L. M., \& Degenhardt, M. (2007). Increased lactation risk for late preterm infants and mothers: Evidence and management strategies to protect breastfeeding. Journal of Midwifery and Womens Health, 52(6), 579-587.

Miles, M. B., \& Huberman, A. M. (1994). Within-case displays: Exploring and describing. In Qualitative data analysis: An expanded sourcebook (2nd ed., pp. 90-142). Thousand Oaks, CA: Sage.

Motzfeldt, K., Lilje, R., \& Nylander, G. (1999). Breastfeeding in phenylketonuria. Acta Paediatrica Supplement, 88(432), 25-27.

National Institutes of Health Consensus Development Panel. (2001) National Institutes of Health Consensus Development Conference Statement: Phenylketonuria: Screening and management. Pediatrics, 108(4), 972-982.

National Newborn Screening and Genetics Resource Center. (2009). National newborn screening 2006 incidence report. Austin TX: National Newborn Screening and Genetics Resource Center, Retrieved from http://genes-r-us.uthscsa.edu/sites/genes-rus/files/resources/genetics/2006datareport.pdf

National PKU Alliance. (2011). My PKU binder. Tomahawk, WI: Author.

Nelson, A., \& Sethi, S. (2005). The breastfeeding experiences of Canadian teenage mothers. Journal Obstetric, Gynecologic, and Neonatal Nursing, 34(5), 615-624. doi:10.1177/08842175052 80279

Northwest Regional Newborn Screening Program. (2010). Oregon's Practitioner Manual. Portland, OR: Oregon Health Authority Public Health. Retrieved from https://public.health.oregon.gov/ LaboratoryServices/NewbornScreening/Documents/nbspract/ manual.pdf

Pangkanon, S., Charoensiriwatana, W., Janejai, N., Boonwanich, W., \& Chaisomchit, S. (2009). Detection of phenylketonuria by the newborn screening program in Thailand. Southeast Asian Journal of Tropical Medicine and Public Health, 4O(3), 525-529

Patton, M. Q. (2002). Qualitative analysis and interpretation. In Qualitative research \& evaluation methods (3rd ed., pp. 541-588). Thousand Oaks, CA: Sage.

PKU News. (2006). Tips for breastfeeding a baby with PKU. Retrieved from http://www.pkunews.org/diet/tipsBaby.htm

Saldana, J. (2009). First cycle coding methods. In The coding manual for qualitative researchers (pp. 45-148). Thousand Oaks, CA Sage.

Segev, R., Abraham, S., Anikster, U., \& Schwartz, G. (2004). The incidence and duration of breastfeeding in the PKU clinic. Paper presented at the Dietary Management of Inborn Errors of Metabolism, London, England.

Tuncbilek, E., \& Ozguc, M. (2007). Application of medical genetics in Turkey. Turkish Journal of Pediatrics, 49(4), 353-359.

van Rijn, M., Bekhof, J., Dijkstra, T., Smit, P. G., Moddermam, P., \& van Spronsen, F. J. (2003). A different approach to breastfeeding of the infants with phenylketonuria. European Journal of Pediatrics, 163, 323-326. 
van Spronsen, F. J., van Rijn, M., Dorgelo, B., Hoeksma, M., Bosch, A. M., Mulder, M. F., ... Verkerk, P. H. (2009). Phenylalanine tolerance can already reliably be assessed at the age of 2 years in patients with PKU. Journal of Inherited Metabolic Disease, 32(1), 27-31. doi:10.1007/s10545-008-0937-3

Zhan, J. Y., Qin, Y. F., \& Zhao, Z. Y. (2009). Neonatal screening for congenital hypothyroidism and phenylketonuria in China. World Journal of Pediatrics, 5(2), 136-139. doi:10.1007/s12519-0090027-0

Zschocke, J., Mallory, J. P., Eiken, H. G., \& Nevin, N. C. (1997). Phenylketonuria and the peoples of Northern Ireland. Human Genetics, 100(2), 189-194. 